ISSN 0258-7122

Bangladesh J. Agril. Res. 35(2) : 279-285, June 2010

\title{
EFFECT OF MILD STRAIN ON SEVERITY OF PRSV-W INFECTION
}

\author{
M. F. RAHMAN ${ }^{1}$, M. A AKANDA ${ }^{1}$ AND M. Z. A. SARKAR ${ }^{2}$
}

\begin{abstract}
Studies were conducted to develop mild/avirulent strain of PRSV-W using nitrous acid, sodium azide and UV-radiation for the mutagenic treatments. Among the three mutagens' sodium azide at $3 \%, 4 \%$, and $5 \%$, and nitrous acid at $0.1 \mathrm{M}$ and $0.125 \mathrm{M}$ were proved to be effective in producing mild/avirulent strains of PRSV-W, while UV-radiation was proved to be ineffective. Evaluation on the effectivity of mild/avirulent strains in net house in protecting severe strain of PRSV-W proved that the efficiency of mild/avirulent strain to protect the severe strain of the virus was dependent upon the time gap between the mild strain inoculation and challenge inoculation. The challenge inoculation with the severe strain of PRSV-W after 12 days of mild strain inoculation could confer the cross-protection in about 64\% pumpkin plants upto 40 days. The presence of mild/avirulent strains of PRSV-W in the asymptomatic plants challenged with severe strain of PRSV-W was tested by mechanical inoculation of Chenopodium amaranticolor to observe the development of characteristic local lesions of PRSV-W.
\end{abstract}

Keywords: PRSV, cross protection.

\section{Introduction}

Pumpkin (Cucurhita moschata Poir) belonging to the family Cucurbitaceae is an important vegetable crop of tropical and subtropical regions of the world. Virus diseases are responsible for huge economic loss of different agricultural crops throughout the world (Bos, 1983). The control of many viral diseases, especially in the tropical countries is difficult for several reasons, namely unavailability of virus resistant or tolerant cultivar, presence of virus and their vectors round the year and growing of crops in numerous small plots over a large area with little isolation (Gonsalves, 1989). More than 25 viruses have been reported to infect the crops of Cucurbitaceae in the field (Lovisolo, 1980). Among them, Papaya ringspot virus - water melon strain (PRSV-W) is regarded as one of the most destructive pathogen infecting cucurbits causing significant reduction in yield (Rezende and Pacheco, 1998). PRSV-W was first reported in Citrullus lanatus by Webb (1965). Akanda (1991) reported that PRSV-W may cause 70-100\% yield reduction of cucurhits depending upon the stage of infection in Bangladesh.

\footnotetext{
${ }^{1}$ Scientific officer (Plant Pathology), Wheat Research Centre, Bangladesh Agricultural Research Institute (BARI), Gazipur, ${ }^{2}$ Professor, Dept. of Plant Pathology, Bangabandhu Sheikh Mujibur Rahman Agricultural University (BSMRAU), Gazipur, ${ }^{3}$ Assistant Director (Contract Growers), BADC, Gazipur, Bangladesh.
} 
Cross-protection is a technique discovered by Mckinney in 1929 that involves inoculation of a mild/avirulent strain into a susceptible host plant to protect it from the subsequent attack of the severe strain of that virus. The mild/avirulent strain of the virus becomes systemic in the plant within a few days. The severe strain of the virus when attack the plant becomes immediately encapsidated and fails to multiply. This is the basic principle of this technique. The cross protection could he achieved by developing the mild strains through mutagenic treatments. Nitrous acid, sodium azide, and UV-radiation are more frequently used as mutagenic agents for the development of mild/avirulent strains of the viruses for using in cross protection (Mckinney, 1929; Mowlick, 2002; Basu, 2004).

The development and selection of' mild strains of PRSV-P has been successfully done and used for cross protection by Yeh et al. (1988). PRSV-W have been controlled successfully by cross-protection reported in Brazil and some other cucurbits growing countries (Rezende and Pacheco, 1998; Lecoq et al., 1991; Wang el al., 1991). So, the successful applications of cross protection in many advanced and developed countries for the management of some selective viral diseases of crop plants suggest that the technique might be a promising one for Bangladesh also for the management of PRSV-W of pumpkin. Considering the facts mentioned earlier, the research programme was designed:

1. to develop mild/avirulent strains of PRSV-W through mutagenic treatment and

2. to test the effectivity of mild strain of PRSV-W in controlling the virus.

\section{Materials and Method}

The experiment was conducted in the insect proof net house of Plant Pathology Laboratory of Bangabandhu Sheikh Mujibur Rabman Agricultural University (BSMRAU), Gazipur during November 2003 to June 2004.

Local pumpkin varieties were used for this experiment. Forty pumpkin seedlings were inoculated with the PRSV-W infected samples and 10 seedlings were maintained as control. After germination, fully expanded cotyledons plants were inoculated. Before inoculation, the cotyledons were dusted with 600- mesh carborundum powder. The samples were prepared by macerating $0.5 \mathrm{~g}$ preserved leaf samples in $5 \mathrm{ml}$ of $0.05 \mathrm{M}$ sodium phosphate buffer, $\mathrm{p}^{\mathrm{H}} 7.1$ The extracted sap was then rubbed on to the cotyledons by finger after rubbing with the sap, the inoculated cotyledons were washed with sterile distilled water. The plants were kept under observation for symptoms development. Similar procedures were followed to inoculate the leaves of Chenopodium amaranticolor, which was used as a local lesion host to check the PRSV-W infection.

The samples were selected on the basis of symptoms and the results of DASELISA to develop mild/avirulent strains through mutagenic treatments. 
The PRSV-W infected samples were collected based on the results of symptomatological study and DAS-ELISA following the method suggested by Noordam (1973). The preserved PRSV-W infected pumpkin samples were inoculated to the cotyledon of healthy pumpkin seedlings for the propagation of the virus according to the method of Noordam (1973).

Seedlings of local indigenous variety of pumpkin was raised and maintained as previous. These pumpkin seedlings were used to test the treatment. Solution of sodium azide was prepared and ultraviolet radiation was used for mutagenic treatment following the method of Mowlick (2002).

A series of sodium solution i.e., at $4 \%, 3 \%, 2 \%$, and $1 \%$ were prepared from the $5 \%$ solution of sodium azide and preserved separately for use. The exposure times to UV-radiation were I mm, $2 \mathrm{~mm}, 3 \mathrm{~mm}, 4 \mathrm{~mm}$, and $5 \mathrm{~mm}$ using UV light in the clean bench available in the Laboratory of BSMRAU. A series of nitrous acid solution i.e.. $0.05 \mathrm{M}, 0.07 \mathrm{M}, 0.1 \mathrm{M}$, and $0.125 \mathrm{M}$ were prepared according to the procedures followed by Yeh et al (1984).

Severely PRSV-W infected pumpkin leaves were ground in $0.05 \mathrm{M}$ sodium phosphate buffer $\mathrm{p}^{\mathrm{H}} 7.1(\mathrm{lg} / \mathrm{l} 0 \mathrm{ml})$. Then the maccrated leaf tissues were treated with different concentrations of sodium azide (i.e., at $1 \%, 2 \%, 3 \%, 4 \%$, and $5 \%$ ), different concentrations of nitrous acid $(0.05 \mathrm{M}, 0.075 \mathrm{M}, 0.1 \mathrm{M}$, and $0.125 \mathrm{M})$ each for 10 minutes. In case of UV radiation treatment, the maccrated leaf tissues were filtrated through cheese cloth and crude sap was placed in five Petri dishes. Those were exposed under UV radiation in the clean bench for $1 \mathrm{~min}, 2 \mathrm{~min}, 3$ min, $4 \mathrm{~min}$, and 5 minutes for treatment. All those samples were then immediately inoculated to the cotyledon of pumpkin seedlings. For each treatment, 10 seedlings were used and the treated seedlings were maintained in an insect proof net house. The same number of plants for each treatment was inoculated with the fresh sap of PRSV-W sample using $0.05 \mathrm{M}$ sodium phosphate buffer $\mathrm{P}^{\mathrm{H}} 7.1$ and carborundum powder those were treated as control.

The pumpkin seedlings inoculated with the sap of PRSV-W infected leaves treated with mutagens were evaluated upto three weeks (21 days) based on the symptom development. The asymptomatic plants were tested by inoculating the sap extracted from the leaves in Chenopodium amaranticolor. The mild/avirulent strains of PPSV-W were selected from this study for further evaluation.

The selected mild/avirulent strains were sap inoculated on the cotyledon of each pumpkin seedling and then inoculated with the severe strains of PPSV-W in the in foliate after 4 th, $8^{\text {th }}$, and $12^{\text {th }}$ days of mild strain inoculation called challenge inoculation. The control plants were inoculated at cotyledonery stage with the severe strains of PRSV-W only. All the plants were observed for symptoms development upto 40 days of challenge inoculation with 10 days interval. In all, 14 plants were used for the test. 
The presence of mild strain in the asymptomatic plants were tested by inoculating Chenopodium amaranticolor with the sap of the symptom less plants to observe the characteristic local lesion development as found in PRSV-W infection. The mechanical inoculation method was employed as described by Noordam (1973).

\section{Results and Discussion}

The results of the mutagenic treatments to develop mild strain of PRSV-W are shown in Table 1. It was observed that sodium azide $\left(\mathrm{N}_{\mathrm{a}} \mathrm{N}_{3}\right)$ at $3 \%, 4 \%$, and $5 \%$ were found to produce mild strains of PRSV-W. A total of 7, 2, and 1 pumpkin plants out of 10 were found to develop mild, moderate, and severe symptoms, respectively, when inoculated with $3 \% \mathrm{~N}_{\mathrm{a}} \mathrm{N}_{3}$ treated sap 7 and 3 plants out of 10 were found to develop mild, moderate symptoms, respectively, when inoculated with $4 \% \mathrm{~N}_{\mathrm{a}} \mathrm{N}_{3}$ treated sap. On the other hand, $5 \% \mathrm{~N}_{\mathrm{a}} \mathrm{N}_{3}$ sap treated pumpkin plants developed mild and moderate symptoms, respectively, in 8 and 2 plants out of 10. There were no plants those showed severe symptoms in both the cases (Table 1). The two concentrations of $\mathrm{N}_{\mathrm{a}} \mathrm{N}_{3}$ i.e., at $1 \%$ and $2 \%$ developed moderate symptoms in 1 and 2 plants, respectively, out of 10 . These two concentrations of sodium azide proved to be ineffective in producing mild symptom in any plant.

In the present study, UV-radiation was proved to he ineffective in producing mild or moderate symptoms in any plant except in case of 4 minutes exposure which produced moderate symptoms in 2 plants out of 10 pumpkin plants (Table $1)$.

Nitrous acid @ 0.1M and 0.125M treatment were proved to be effective in producing mild/avirulent strain of PRSV-W and $0.1 \mathrm{M}$ nitrous acid was found to be the best. The pumpkin plants inoculated with $0.1 \mathrm{M}$ nitrous acid treated sap developed mild, moderate and severe symptoms in 7.2 and 1 plant, respectively, out of 10 . The pumpkin plants inoculated with $0.125 \mathrm{M}$ nitrous acid developed mild, moderate, and severe symptoms, respectively, in sap 6, 2 and 2 out of 10 plants. The pumpkin plants inoculated with $0.05 \mathrm{M}$ nitrous acid treated sap developed mild, moderate, and severe symptoms, respectively, in 3, 2, and 5 plants out of 10 . The pumpkin plants inoculated with $0.075 \mathrm{M}$ nitrous acid treated sap induced mild, moderate, and severe symptoms in 4.1 and 5 plants out of 10 , respectively (Table 1 ).

Gonsalves (1989) conducted research on cross protection technique for controlling plant viruses. Among the viruses, PRSV was successfully controlled through cross protection in Taiwan in papaya. Nitrous acid induced mutants (PRV HA 5-1 and 6-1) were designed for cross protection tests. Mowlick (2002) conducted an experiment to develop mild strains of PRSV-P in papaya by using 
mutagenic treatments at BSMRAU. He observed that the mutagenic treatments on extraction of PRSV-P infected leaves with $0.075 \mathrm{M}$ nitrous acid, $2 \%$ sodium azide and exposure to UV radiation for 1 and 2 minutes were found to be best in the production of effective mild strains of PRSV-P to use in cross protection. So far it was the first report on cross protection in Bangladesh.

Table 1. Development of mild strain of PRSV-W by mutagenic treatment.

\begin{tabular}{|c|c|c|c|c|}
\hline \multirow{2}{*}{ Mutagens } & \multirow{2}{*}{$\begin{array}{l}\text { Concentration/ } \\
\text { Exposure time }\end{array}$} & \multicolumn{3}{|c|}{ No. of plants showed symptoms* } \\
\hline & & Mild & Moderate & Severe \\
\hline \multirow{5}{*}{ Sodium Azide } & $01 \%$ & 0 & 1 & 9 \\
\hline & $02 \%$ & 0 & 2 & 8 \\
\hline & $03 \%$ & 7 & 2 & 1 \\
\hline & $04 \%$ & 7 & 3 & 0 \\
\hline & $05 \%$ & 8 & 2 & 0 \\
\hline Control & - & 0 & 0 & 10 \\
\hline \multirow{5}{*}{ UV-radiation } & $01 \mathrm{~mm}$ & 0 & 0 & 10 \\
\hline & $02 \mathrm{~mm}$ & 0 & 0 & 10 \\
\hline & $03 \mathrm{~mm}$ & 0 & 0 & 10 \\
\hline & $04 \mathrm{~mm}$ & 0 & 2 & 8 \\
\hline & $05 \mathrm{~mm}$ & 0 & 0 & 10 \\
\hline Control & - & 0 & 0 & 10 \\
\hline \multirow{4}{*}{ Nitrous acid } & $0.05 \mathrm{M}$ & 3 & 2 & 5 \\
\hline & $0.075 \mathrm{M}$ & 4 & 1 & 5 \\
\hline & $0.10 \mathrm{M}$ & 7 & 2 & 1 \\
\hline & $0.125 \mathrm{M}$ & 6 & 2 & 2 \\
\hline Control & - & 0 & 0 & 10 \\
\hline
\end{tabular}

*Each treatment consists of 10 plants

All the control plants i.e., the plants inoculated with severe strain of PRSV$\mathrm{W}$ produced severe symptoms.

The evaluation of the effectivity of the mild strain in protecting severe strain of PRSV-W was found to be dependent upon the time of challenge inoculation of severe strain after mild strain inoculation. The pumpkin plants challenged with severe strain of PRSV-W at 12 days after mild strain inoculation were found to be most effective in protecting the virus when the test was carried out in an insect proof net house. About $64 \%$ plants remained asymptomatic upto 40 days after challenge inoculation in the trail (Table 2). 
Table 2. Effectivity of mild strain of PRSV-W when challenged with severe.

\begin{tabular}{l|c|c|cc}
\hline \multirow{2}{*}{$\begin{array}{c}\text { Days after challenge } \\
\text { inoculation }\end{array}$} & \multicolumn{4}{|c}{ No. of pumpkin plants showing no severe symptoms } \\
after challenge at day
\end{tabular}

The appearance of chlorotic local lesion in Chenopodium amaranticolor leaves when inoculated with the leaf extract asymptomatic plants of pumpkin previously inoculated with mild strain and challenged with severe strains proved the presence and multiplication of mild strain in the plants.

\section{Conclusion}

The results suggested that among the three mutagens, namely sodium azide, UVradiation, and nitrous acid, two mutagens-sodium azide at $3 \%$, $4 \%$, and $5 \%$, and nitrous acid at $0.1 \mathrm{M}$ and $0.125 \mathrm{M}$ were found to be effective in developing mild/avirulent strain of PRSV-W from the severe strain of the virus. UVradiation was found as ineffective. The time gap between the challenge inoculation with the severe strain after the mild strain inoculation determined the effectiveness of the mild strain in protecting the severe strain. The challenge inoculation by the severe strain of PRSV-W at 12 days of mild strain inoculation conferred cross protection in $64 \%$ plants tip to 40 days after challenged in the net house.

\section{References}

Akanda, A. M. 1991. Studies on the virus and mycoplasma disease of crops in Bangladesh. A Thesis submitted to the Faculty of Agriculture, Kyushu University, Japan for the partial fulfillment of Doctor of agriculture pp. 181

Basu, C. 2004. Control of Zucchini yellow mosaic virus in pumpkin by cross protection. MS thesis. Bangabandhu Sheikh Mujibur Rahman Agricultural University. pp. 61

Bos, L. 1983. Introduction to plant virology. First Edition. Centre for Agricultural Publishing and Ducumentation, Wageningen, the Netherlands. pp 160.

Gonsalves. D. 1989. Cross protection technique for control of plant virus diseases in the tropics, Plant Disease 73: 592-597.

Lecoq H., J. M. Lemaire and C. Wipf-Scheibel. 1991. Control of Zucchini yellow mosaic virus in squash by cross protection. Plant Disease 75: 208-211

Lovisolo, 0. 1980. Virus and viroid diseases of cucurbits. Acta Horticulturae. 88: 33-90.

Mowlick, S. 2002. Investigation to certain aspect of PRSV-P and development of its mild strains using mutagcnic treatments. M.S Thesis, Bangabandhu Sheikh Muibur Rahrnan Agricultural University, pp. 64. 
Noordam, D. 1973. Identification of plant viruses-methods and experiments. Centre for Agricultural Publishing and Documentation, Wageningen, the Netherlands. pp. 207.

Mckinney. H. H. 1929. Mosaic diseases in the Canory Islands, West Africa and Gibralter. Agric, Res 39: 557-578.

Rezende, J. A. M. and D. A. Pacheco. 1998. Control of Papaya ringspot virus- type W in zucchini squash by protection in Brazil. Plant Disease 82: 171-175.

Wang. H. L, D. Gonsalves, R. Provvidenti and H. Lecoq. 1991. Effectiveness of cross protection by a mild strain of Zucchini yelow mosaic virus in cucumber, melon and squash. Plant Disease 75: 203-207.

Webb, R. E. 1965. Waiermelon mosaic virus infecting melons in the USA. Phytopathology 55: 1379.

Yeh, S. D., D. Gonsalves, H. L. Wang, R. Namba, and R. J Chiu. 1988. Control of Papaya ringspot virus by cioss protection. Plant Disease 72(5): 375-380.

Yeh, S. D., D. Gonsalves and R Provvidenti. 1984. Comparative studies on host range and serology of Papaya ringspot virus and watermelon mosaic virus. Phytopathology 74(9): 1081-1085. 